\title{
The impact of perceived heat stress symptoms on work-related tasks and social factors: A cross-sectional survey of Australia's Monsoonal North
}

\author{
Sarah Carter $^{\mathrm{a}, *, 1}$, Emma Field ${ }^{\mathrm{e}, \mathrm{f}}$, Elspeth Oppermann ${ }^{\mathrm{d}}$, Matt Brearley ${ }^{\mathrm{b}, \mathrm{c}, \mathrm{d}}$

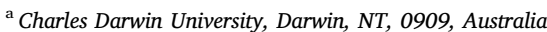 \\ ${ }^{\mathrm{b}}$ National Critical Care and Trauma Response Centre, Level 8 Royal Darwin Hospital, Rocklands Drive, Tiwi, 0810, NT, Australia \\ ${ }^{c}$ Thermal Hyperformance, PO Box 1356, Howard Springs, 0835, NT, Australia \\ ${ }^{\mathrm{d}}$ Northern Institute, Charles Darwin University, Darwin, NT, 0909, Australia \\ ${ }^{\mathrm{e}}$ Menzies School of Health Research, Level 1, 147 Wharf Street, Spring Hill, 4000, QLD, Australia \\ ${ }^{\mathrm{f}}$ Australian National University, National Centre for Epidemiology and Population Health, 62 Mills Road, Acton Australian Capital Territory, 2601, Australia
}

\section{A R T I C L E I N F O}

\section{Keywords:}

Heat related illness

Northern Australia

Thermoregulation

Workplace health and safety

\begin{abstract}
A B S T R A C T
Heat poses a significant occupational hazard for labour-intensive workers in hot and humid environments. Therefore, this study measured the prevalence of heat-stress symptoms and impact of heat exposure on labourintensive industries within the Monsoonal North region of Australia. A cohort of 179 workers completed a questionnaire evaluating environmental exposure, chronic (recurring) and/or severe (synonymous with heat stroke) symptoms of heat stress, and impact within work and home settings. Workers reported both chronic $(79 \%)$ and severe $(47 \%)$ heat stress symptoms, with increased likelihood of chronic symptoms when exposed to heat sources (OR 1.5-1.8, $p=0.002-0.023$ ) and decreased likelihood of both chronic and severe symptoms when exposed to air-conditioning (Chronic: OR 0.5, $p=<0.001$, Severe: OR 0.7, $p=0.019$ ). Negative impacts of heat exposure were reported for both work and home environments (30-60\% respectively), highlighting the need for mitigation strategies to reduce occupational heat stress in the Monsoonal North.
\end{abstract}

\section{Introduction}

Based on the Köppen climate model (Stern et al., 2000), the most Northern regions of Australia encompass both tropical and equatorial zones, experiencing annual dry (May to September) and wet seasons (October to April). Averaged minimum and maximum ambient temperatures of $16^{\circ} \mathrm{C}-33^{\circ} \mathrm{C}$ during the dry season are coupled with low humidity (57$35 \%$ relative humidity, respectively), in contrast the wet season experiences frequent monsoonal activity, elevated peak humidity ( $>76 \%$ relative humidity) with similar ambient temperatures of $22^{\circ} \mathrm{C}-33^{\circ} \mathrm{C}$ (Australian Bureau of Meteorology, 2017). The interim period, colloquially termed the 'build-up' in reference to the daily accumulation of heat and environmental moisture results in ambient temperatures of $23{ }^{\circ} \mathrm{C}-36{ }^{\circ} \mathrm{C}$ with increasing humidity (66-40\% relative humidity, respectively) and frequency of warm days (Australian Bureau of Meteorology, 2017), deemed the harshest period for thermoregulation (McDermott et al., 2017).

Overall, Australia is expected to experience increased mean, maximum and minimum temperatures of $0.6-1.3^{\circ} \mathrm{C}$ by 2030 (Steffen et al.,
2017). Such increases would translate to a greater frequency of days warmer than $35^{\circ} \mathrm{C}$. For example, Darwin, a key population centre and industrial hub of Northern Australia, may endure 43 days above $35^{\circ} \mathrm{C}$ by 2030 , and 265 days greater than $35^{\circ} \mathrm{C}$ by 2090 . The latter projection being approximately 20 times the current mean 12 days greater than $35{ }^{\circ} \mathrm{C}$ (Commonwealth Scientific and Industrial Research Organisation and Bureau of Meteorology, 2015). Additionally, regional thermal mapping (imaging) and analysis of meteorological data (2006-2016) raised concern due to low wind speeds (3.4-4.1 m/second) with high ambient temperatures and relative humidity (Santamouris et al., 2017).

Prolonged physical work in hot and humid environments increases the net heat load to which an individual is exposed, otherwise known as heat stress. Heat stress is well-known to impact upon acute health status and may manifest in a range of heat-related illnesses. Mild symptoms include skin rashes (Donoghue and Sinclair, 2000), muscular cramps (Donoghue et al., 2000), headaches, nausea, dizziness, weakness, and fatigue (Glazer, 2005). Whereas confusion, irrational behaviour, low coordination, fainting, vomiting, convulsions, and loss of consciousness

\footnotetext{
* Corresponding author.

E-mail addresses: sarah.carter@sydney.edu.au (S. Carter), emma.field@menzies.edu.au (E. Field), elspeth.oppermann@tum.de (E. Oppermann), matt.brearley@nt.gov.au (M. Brearley).

${ }^{1}$ Present address: Thermal Ergonomics Laboratory, Faculty of Health Sciences, The University of Sydney, 75 East St, Lidcombe NSW 2141, Australia.
} 
(Shapiro and Seidman, 1990) are considered severe symptoms. The traditional theory asserts heat stroke is synonymous with an elevated core body temperature $\left(>40^{\circ} \mathrm{C}\right)$, however, heat stroke can occur with core body temperatures below $40^{\circ} \mathrm{C}$. For instance, with prolonged reduction in blood flow to the splanchnic region from the increased requirement for blood flow to dissipate heat at the skin surface, hypoxia and cellular death occur at the intestinal barrier leading to increased risk of sepsis through translocation of bacteria into systemic circulation (Hall et al., 1999; Lambert et al., 2002).

Although thermoregulatory research from Northern Australia field settings is limited, monitoring of miners (Brake and Bates, 2001; Donoghue et al., 2000; Hunt, Parker and Stewart, 2013), electrical utility workers (Brearley et al., 2015), emergency responders (Brearley, 2016; Brearley et al., 2013; Brearley et al., 2011), and soldiers (Cotter et al., 2000) within this region has identified the substantial physiological impost of working in hot and humid conditions in Northern Australia. Moreover, research within this region is emerging on the social factors affecting worker safety, productivity and health (Jia et al., 2016; Oppermann et al., 2017). As heat may exacerbate pre-existing mental health issues, suicide rates, and violence (Anderson, 2016; Hansen et al., 2008), the wellbeing of workers within Northern Australia represents a current issue for industries with economic ramifications (Zander et al., 2015).

Additionally, exposure to the Monsoonal North's climate may also limit physical (Nybo, 2008; Snook and Ciriello, 1974) and cognitive capacity (Bandelow et al., 2010; Patterson et al., 1997; Taylor et al., 2015) required to conduct work. This is an important consideration for industries of Northern Australia including agriculture, mining, oil and gas, and construction. Climatic impacts on worker health and productivity would likely impact regional and national prosperity, given the substantial contributions these industries deliver to the Australian economy (Jay and Brotherhood, 2016; Hanna et al., 2011). Yet, research examining physiological responses to working in hot and humid conditions are almost exclusively focused on acute exposure, commonly seen in one singular event or over a short period of abnormally hot weather. As a result, less is known of the heat stress endured by occupational groups exposed to consecutive days on a regular schedule of work in the Monsoonal North. Recent literature examining whole-body heat loss in the second day of work in young and older men found decreased whole-body heat loss in older men (Notley et al., 2018a,b). Whilst promising, further research is still required to separate the combined stressors of fluid depletion, exposure to heat sources and physical work as potential stressors and longer periods of work to replicate the workforce are required. Therefore, this research sought to expand upon previous work within a limited cohort (Brearley, Harrington, Field, Oppermann, \& Lee, Unpublished Results) due to anecdotal and descriptive accounts of heat-related illness within workers in the Monsoonal North (Oppermann et al., 2017). Further, to verify the prevalence of heat stress symptoms within environmental conditions conducive to heat illness and the resultant effects in the work and home environments.

\section{Material and methods}

\subsection{Study population}

Labour-intensive workers within the Monsoonal north regions of Australia (depicted as the tropical region in Fig. 1) were invited to participate in a cross-sectional questionnaire hosted by SurveyMonkey (San Mateo, CA, USA) via email and workplace presentations. The questionnaire related to the October to December period of 2016 (build-up season), assessing heat exposure in the work environment, negative impacts, and symptoms of heat exposure. Parameters for inclusion involved outdoor exposure more than some of the time, direct sunlight more than some of the time and air-conditioning less than most of the time. This study was approved by Charles Darwin University
Human Research Ethics Committee with no personal identifiers recorded within or before the survey. Electronic informed consent was provided by participants prior to survey commencement and data were collected between January-March 2017.

\subsection{Questionnaire design}

Survey questions were adapted from Brearley et al. (Unpublished Results), incorporating elements from previous work by Hunt (2011), and Xiang et al. (2016). Initial questions addressed demographics including age, gender, home and work locations, occupation and industry. Work conditions were assessed based on their exposure to the outdoors, direct sunlight, hot surfaces and air-conditioning (all, most, half, some, or none of the time, respectively). Workplace attire was selected by workers from a list of separate clothing items commonly utilised within the included industries and occupations (long/short pants and shirt, coveralls, jacket, vests, boots, hats, protective equipment: gloves, hard hat, aprons). Negative impacts of heat exposure were assessed based on bi-weekly frequency (daily, weekly, fortnightly, rarely, never).

Workers reported perceived symptoms from heat exposure which were classified as either mild to moderate (feeling hot, heavy sweating, thirst, fatigue, headache, irritable, clammy skin, rash, loss of concentration, muscle cramps, muscle weakness, dizziness) or severe (confusion, irrational behaviour, low coordination, loss of consciousness, convulsions, fainting, vomiting). From symptom frequency and severity, two definitions were drawn for chronic and severe heat stress cases based on clinical case definitions of heat illness (heat exhaustion and heat stroke). Chronic was defined as workers reporting daily or weekly frequency of symptoms synonymous with heat exhaustion including feeling hot, heavy sweating, thirst, fatigue, headache, irritable, clammy skin, rash, loss of concentration, muscle cramps, muscle weakness, and dizziness. Severe cases were defined by any report of confusion, irrational behaviour, low coordination, loss of consciousness, convulsions, fainting, or vomiting.

\subsection{Statistical analysis}

Data were exported from SurveyMonkey, analyses were performed in STATA 14.2 and STATA 15 (StataCorp, Texas, USA). Categorical variables were summarised by counts and percentages rounded to whole numbers. Logistic regression (univariate) was performed for the following outcomes: chronic heat stress cases, severe heat stress cases and exposure to conditions. Odds ratios (OR) were estimated for each model with $95 \%$ confidence intervals (CI). Where collinearity was found with each level of frequency, data were treated as binary for the analysis.

\section{Results}

\subsection{Demographic characteristics}

A total of 222 workers commenced the electronic survey, however, only 183 completed all responses, resulting in a total of 140-179 responses to each question. Of the 183 respondents, 143 (80\%) were male, and the majority were 40 years or younger (77\%). Ninety-three respondents (53\%) worked within the Northern Territory, 48 (27\%) in Queensland and $36(20 \%)$ in Western Australia. Workers lived in their current location under 1 year (7\%), between 1 and 5 years (20\%), between 5 and 10 years (41\%) and over 10 years (32\%). While work shift length varied from less than six to greater than $12 \mathrm{~h}$, most participants (76\%) worked shifts between six to $8 \mathrm{~h}$. A further 35 workers (20\%) reported working $10-12 \mathrm{~h}$, and $8(4 \%)$ over $12 \mathrm{~h}$. All respondents answered a question regarding workplace attire worn at work. The majority of workers reported wearing boots (92\%), long pants (76\%) and long sleeve shirts whilst at work (73\%), however, no associations were observed between heat stress symptoms and variations in clothing ensembles. 

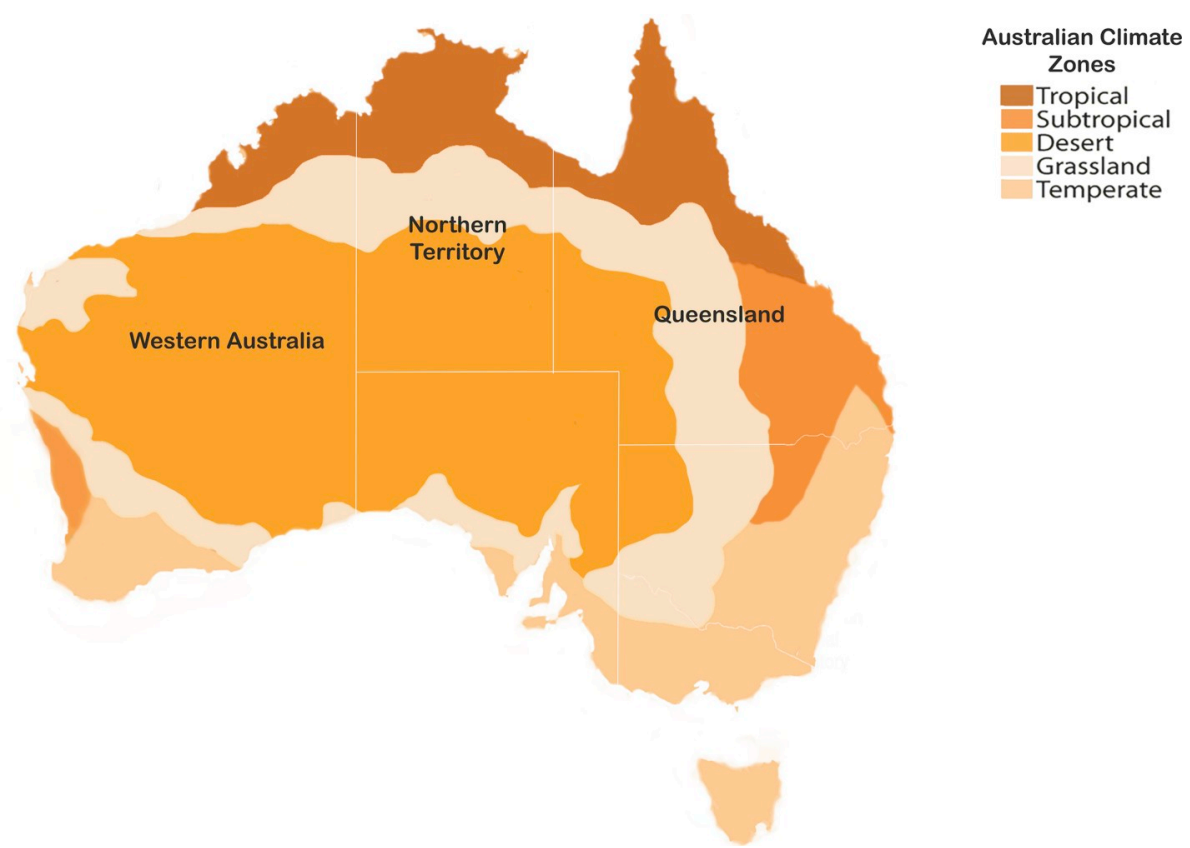

Fig. 1. Australian climatic zones (Adapted from Commonwealth Scientific and Industrial Research Organisation and Bureau of Meteorology, 2016).

\subsection{Heat stress symptoms}

Chronic heat stress symptoms were reported by $142(79 \%)$ respondents and severe heat stress symptoms were reported by 84 (47\%) as depicted in Table 1.

\subsection{Worker industry and occupations}

The majority of respondents were employed in public administration and safety (28\%), and electricity, water and waste services (24\%) industries. With the majority of workers within subsequent occupations populated by tradespersons and related workers (46\%) and farming, gardening and landscape workers (22\%). A negative association was demonstrated between public administration and safety workers with chronic heat stress cases (OR $0.4, p=0.037$ ). Similarly, the subsequent occupation of government and emergency workers saw a strong negative association between chronic heat stress cases (OR 0.8 , $p=<0.001)$. Whilst tradespersons and related workers had strong associations and increased odds for both chronic (OR 3.1, $p=0.012$ ) and severe (OR 1.8, $p=0.043$ ) heat stress cases (Table 2). Managers or supervisors, representing $21 \%$ of respondents, reported decreased odds of experiencing severe heat stress symptoms (OR $0.3, \mathrm{p}=0.005)$.

\subsection{Workplace conditions}

Respondents had exposure to outdoor conditions (59\%) and direct sunlight (50\%) most or all of the time, respectively (Fig. 2). Exposure to hot surfaces was reported for all respondents (86\%) with 30\% exposed most or all of the time. Air-conditioning was available for most respondents (71\%), however, only $14 \%$ had exposure most of the time.

Table 1

Workers perceived heat stress symptoms.

\begin{tabular}{|c|c|c|c|c|c|c|c|}
\hline Symptoms & & $\mathrm{n}$ & Daily & Weekly & Fortnightly & Rarely & Never \\
\hline \multirow[t]{14}{*}{ Mild to Moderate } & Feeling Hot & 175 & $102(58.3)$ & $29(16.6)$ & $16(9.1)$ & $20(11.4)$ & $8(4.6)$ \\
\hline & Heavy sweating & 176 & $95(54.0)$ & $37(21.0)$ & $13(7.4)$ & $18(10.2)$ & $13(7.4)$ \\
\hline & Thirst & 174 & $106(60.9)$ & $25(14.4)$ & $10(5.7)$ & 29 (16.7) & $4(2.3)$ \\
\hline & Fatigue & 178 & $19(10.7)$ & $44(24.7)$ & $36(20.2)$ & $56(31.5)$ & $23(12.9)$ \\
\hline & Headache & 173 & $7(4.0)$ & $29(16.8)$ & $39(22.5)$ & $70(40.5)$ & $28(16.2)$ \\
\hline & Irritability & 172 & $6(3.5)$ & $30(17.4)$ & $17(9.9)$ & $57(33.1)$ & $62(36.0)$ \\
\hline & Clammy skin & 174 & $18(10.3)$ & $14(8.0)$ & $7(4.0)$ & $38(21.8)$ & $97(55.7)$ \\
\hline & Rash & 171 & $11(6.4)$ & $12(7.0)$ & $19(11.1)$ & $55(32.2)$ & 74 (43.3) \\
\hline & Concentration loss & 172 & $12(7.0)$ & $17(9.9)$ & $19(11.0)$ & $55(32.0)$ & $69(40.1)$ \\
\hline & Muscle cramps & 172 & $4(2.3)$ & $20(11.6)$ & 17 (9.9) & $71(41.3)$ & $60(34.9)$ \\
\hline & Muscle weakness & 171 & $3(1.8)$ & $13(7.6)$ & $16(9.4)$ & $66(38.6)$ & $73(42.7)$ \\
\hline & Dizziness & 171 & $4(2.3)$ & $7(4.1)$ & $12(7.0)$ & $59(34.5)$ & $89(52.0)$ \\
\hline & Nausea & 171 & $1(0.6)$ & $7(4.1)$ & $13(7.6)$ & $53(31.0)$ & $97(56.7)$ \\
\hline & Blurred vision & 170 & $0(0.0)$ & $6(3.5)$ & $6(3.5)$ & $35(20.6)$ & $123(72.4)$ \\
\hline \multirow[t]{7}{*}{ Severe } & Confusion & 172 & $6(3.5)$ & $6(3.5)$ & $7(4.1)$ & 37 (21.5) & $116(67.4)$ \\
\hline & Irrational behaviour & 171 & $5(2.9)$ & $5(2.9)$ & $5(2.9)$ & $36(21.1)$ & $120(70.2)$ \\
\hline & Low coordination & 172 & $2(1.2)$ & $5(2.9)$ & $5(2.9)$ & 25 (14.5) & $135(78.5)$ \\
\hline & Loss of consciousness & 171 & $0(0.0)$ & $0(0.0)$ & $0(0.0)$ & $2(1.2)$ & $169(98.8)$ \\
\hline & Convulsions & 172 & $0(0.0)$ & $0(0.0)$ & $0(0.0)$ & $2(1.2)$ & $170(98.8)$ \\
\hline & Fainting & 170 & $0(0.0)$ & $0(0.0)$ & $1(0.6)$ & $17(10.0)$ & $152(89.4)$ \\
\hline & Vomiting & 171 & $0(0.0)$ & $0(0.0)$ & $0(0.0)$ & $32(18.7)$ & $139(81.3)$ \\
\hline
\end{tabular}

Categorical variables summarised as frequency (percentage of respondents). 
Table 2

Regression analysis of heat stress cases for industry and occupation.

\begin{tabular}{|c|c|c|c|c|c|}
\hline \multirow[t]{2}{*}{ Variable } & & \multicolumn{2}{|l|}{ Chronic cases } & \multicolumn{2}{|l|}{ Severe cases } \\
\hline & & OR $(95 \% \mathrm{CI})$ & $p$ value & OR $(95 \% \mathrm{CI})$ & $p$ value \\
\hline \multirow[t]{5}{*}{ Industry } & Public administration and safety & $0.4(0.2-0.9)$ & 0.037 & $0.7(0.4-1.5)$ & 0.394 \\
\hline & Electricity, water and waste & $3.3(0.7-15.0)$ & 0.110 & $1.5(0.6-3.5)$ & 0.329 \\
\hline & Construction & $1.0(0.5-2.4)$ & 0.898 & $0.7(0.4-1.5)$ & 0.465 \\
\hline & Agriculture, forestry and fishing & $3.2(0.5-14.3)$ & 0.127 & $1.2(0.5-2.7)$ & 0.746 \\
\hline & Other & $0.7(0.3-1.7)$ & 0.439 & $1.3(0.6-2.7)$ & 0.566 \\
\hline \multirow[t]{5}{*}{ Occupation } & Tradespersons and related & $3.1(1.3-7.6)$ & 0.012 & $1.8(1.0-3.5)$ & 0.043 \\
\hline & Farming, gardening \& landscape & $2.1(0.7-6.4)$ & 0.187 & $0.7(0.3-1.5)$ & 0.339 \\
\hline & Government \& emergency & $0.8(0.1-0.3)$ & $<0.001$ & $1.0(0.4-2.5)$ & 0.926 \\
\hline & Labourers and related & $9.5(0.3-3.6)$ & 0.942 & $1.1(0.4-3.4)$ & 0.810 \\
\hline & Other & $0.3(0.1-1.4)$ & 0.134 & $2.7(0.7-11.1)$ & 0.147 \\
\hline
\end{tabular}

Odds ratio (95\% Confidence interval) .

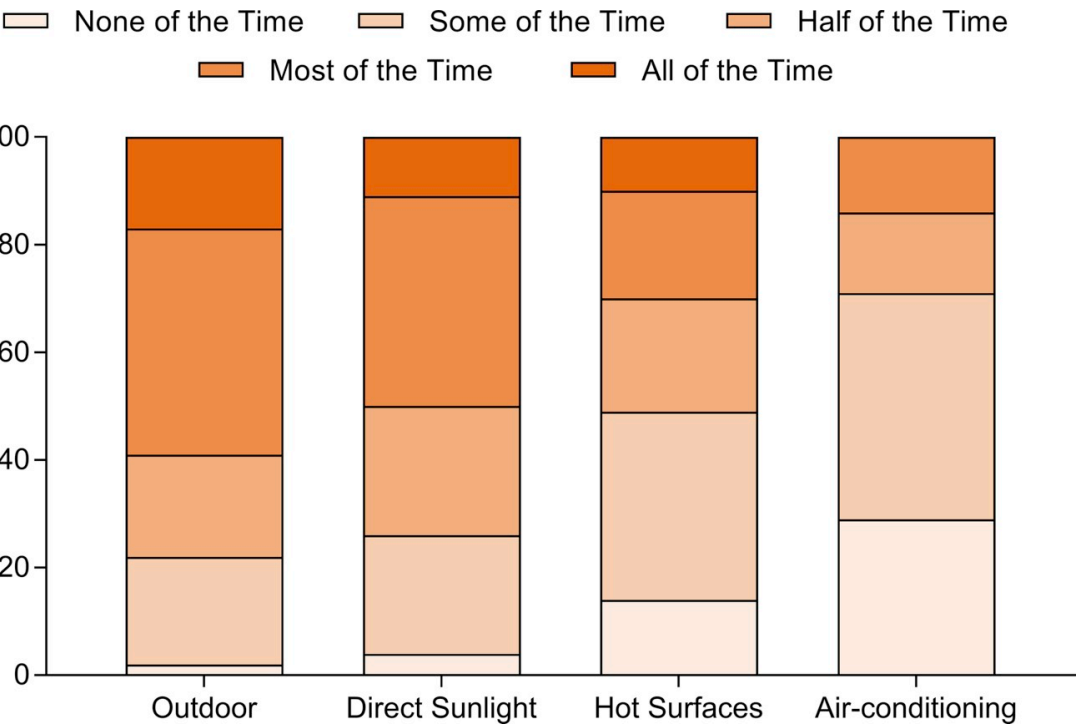

Fig. 2. Exposure to conditions within work environment.

Workers spent more time exposed to outdoor conditions (42\%), direct sunlight (29\%) and hot surfaces (22\%) than managers most or all of the time. Conversely, workers spent less time exposed to air-conditioning in comparison to managers who reported $32 \%$ more exposure to air-conditioning.

Based upon industry, workers from agriculture, forestry and fishing, electricity, water and waste service, and public administration and safety reported the highest exposure to outdoor conditions all or most of the time (62-88\%). Electricity, water and waste service workers also reported the highest exposure to direct sunlight, (all or most of the time) followed by agriculture, forestry and fishing and construction, mining, oil and gas (53-72\%). Nine agriculture, forestry and fishing workers and 13 construction, mining, oil and gas workers reported no access to air-conditioning during work hours (29-38\%). Government and emergency workers were exposed to more direct sunlight and outdoor conditions all or most of the time (73-85\%), whilst tradespersons and related workers were exposed to direct sunlight and outdoor conditions all or most of the time (56-76\%).

Table 3 shows the odds of a worker suffering from chronic heat stress was strongly associated with increased exposure to outdoor conditions (OR 1.7, $p=0.002$ ), hot surfaces (OR 1.6, $p=0.009$ ) and direct sunlight (OR 1.5, $p=0.023$ ). The odds of a worker suffering severe heat stress symptoms were only increased by exposure to hot surfaces (OR 1.4, $p=0.009$ ).

Fig. 3 demonstrates the effect of heat sources on the frequency of chronic heat stress cases, with outdoor exposure exhibiting the most
Table 3

Regression analysis of heat stress cases and exposure.

\begin{tabular}{|c|c|c|c|c|c|}
\hline \multirow{2}{*}{ Variable } & & \multicolumn{2}{|l|}{ Chronic cases } & \multicolumn{2}{|l|}{ Severe cases } \\
\hline & & OR (95\% CI) & $p$ value & OR (95\% CI) & $p$ value \\
\hline \multirow[t]{4}{*}{ Exposure } & Outdoors & $1.7(1.2-2.5)$ & 0.002 & $1.3(0.9-1.7)$ & 0.120 \\
\hline & Sunlight & $1.5(1.0-2.1)$ & 0.023 & $1.1(0.8-1.5)$ & 0.507 \\
\hline & $\begin{array}{l}\text { Hot surfaces/ } \\
\text { machinery }\end{array}$ & $1.6(1.1-1.2)$ & 0.009 & $1.4(1.0-1.8)$ & 0.009 \\
\hline & Air conditioning & $0.5(0.3-0.7)$ & $<0.001$ & $0.7(0.5-0.9)$ & 0.019 \\
\hline
\end{tabular}

Odds ratio (95\% Confidence interval).

dramatic change. In contrast, Fig. 4 demonstrates hot surface exposure is greater for severe heat stress cases than both outdoor exposure and direct sunlight exposure.

Fig. 5 demonstrates the effect of air-conditioning with a clear drop in the frequency of both chronic and severe heat stress symptoms (Odds ratio).

\subsection{Negative impacts of heat}

Both, the speed of task completion and motivation to complete task were the most negatively affected work factors on a daily or weekly basis (Table 4). Least affected were workers ability to understand a task, and their quality of work. Workers reported sport, sleep and appetite were negatively affected by heat on a daily or weekly basis (27-34\%), whilst $25 \%$ of workers reported a negative impact of heat on 
\pm Hot Surfaces $\quad=$ Direct Sunlight $\quad$ Outdoor

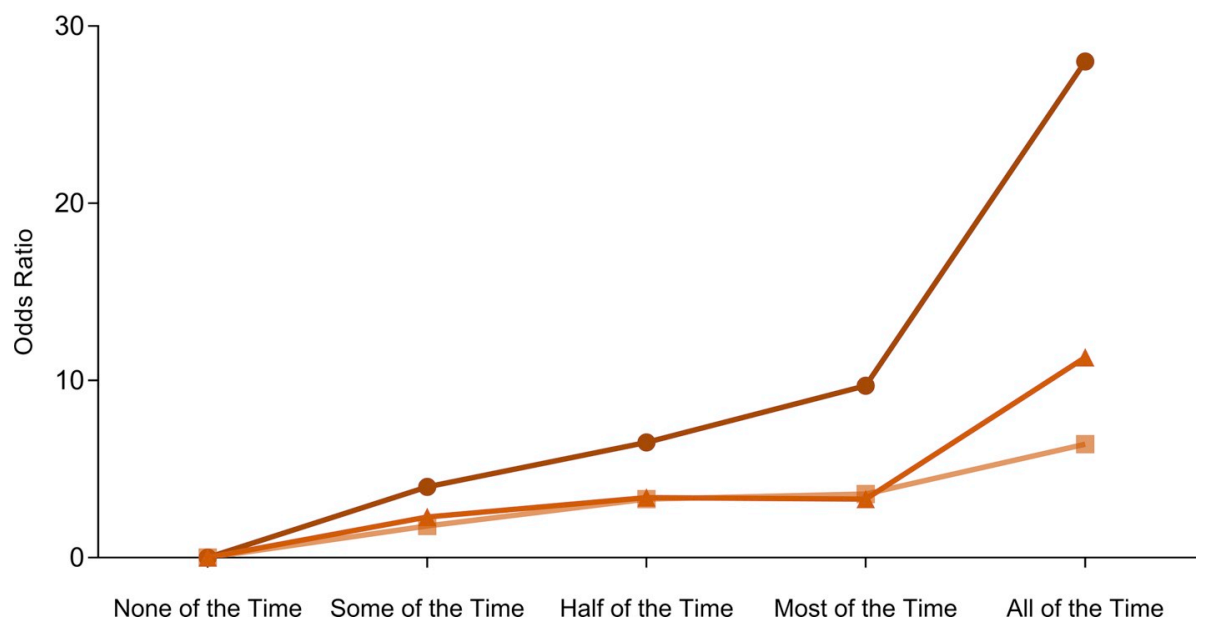

Fig. 3. Incidence of chronic heat stress cases and exposure (Odds ratio).

relationships with friends and family on a daily, weekly or fortnightly basis. A total of $30(17 \%)$ workers utilised sick leave for heat-related issues during the build-up, with 27 of the 30 workers reporting 1-4 days. The overall leave toll was in the range of 63-89 days. Only 15 (9\%) workers sought medical treatment for heat-related issues within a clinic or hospital. Increased odds for chronic and severe heat stress for all negative impacts both at work and at home.

\section{Discussion}

\subsection{Heat exposure and symptom prevalence}

This is the first study to examine a broad cohort of heat-exposed workers within Australia's Monsoonal North, a region which endures seasonally hot and humid conditions. Most respondents (79\%) experienced chronic heat stress symptoms, while approximately half $(47 \%)$ reported severe heat stress symptoms. The results are consistent with descriptive accounts of occupational heat stress within the region (Oppermann et al., 2017), validating the prevalence of heat stress symptoms and the resultant impact on workers perceived productivity and wellbeing. Moreover, chronic heat stress symptoms were more likely for workers exposed to outdoor conditions, direct sunlight, and hot surfaces all or most of the time. Unexpectedly, this study identified exposure to hot surfaces as the only strong association with severe heat stress symptoms, whereas previous survey analysis within the Northern Territory found no association (Brearley et al., Unpublished Results). Our finding are consistent with literature pertaining to ambient smelting environments (Fahed et al., 2018; Giahi et al., 2015; Krishnamurthy et al., 2017). Whilst the association between heat stress symptoms and hot surfaces is not unique to this investigation, it is intuitive that the combination of compounding heat sources within this region are conducive to workers suffering heat stress symptoms.

Hot surfaces within the workplace can include asphalt, concrete, soil, sand, metal, and equipment/machinery. Thus, classifying industries such as construction, mining, agriculture and utilities as susceptible to high radiant heat loads. Such risk classification is consistent with the results of this investigation and the peer-reviewed literature (Brearley et al., 2015; Donoghue et al., 2000; Hunt, Parker and Stewart, 2014; Peiffer and Abbiss, 2013; Xiang et al., 2014). Further, the findings demonstrate a strong positive association between outdoor exposure with both chronic and severe heat stress symptoms in tradespersons and related workers (Brearley et al., Unpublished Results).

\section{$\mp$ Hot Surfaces $\quad \rightarrow$ Direct Sunlight Outdoor}

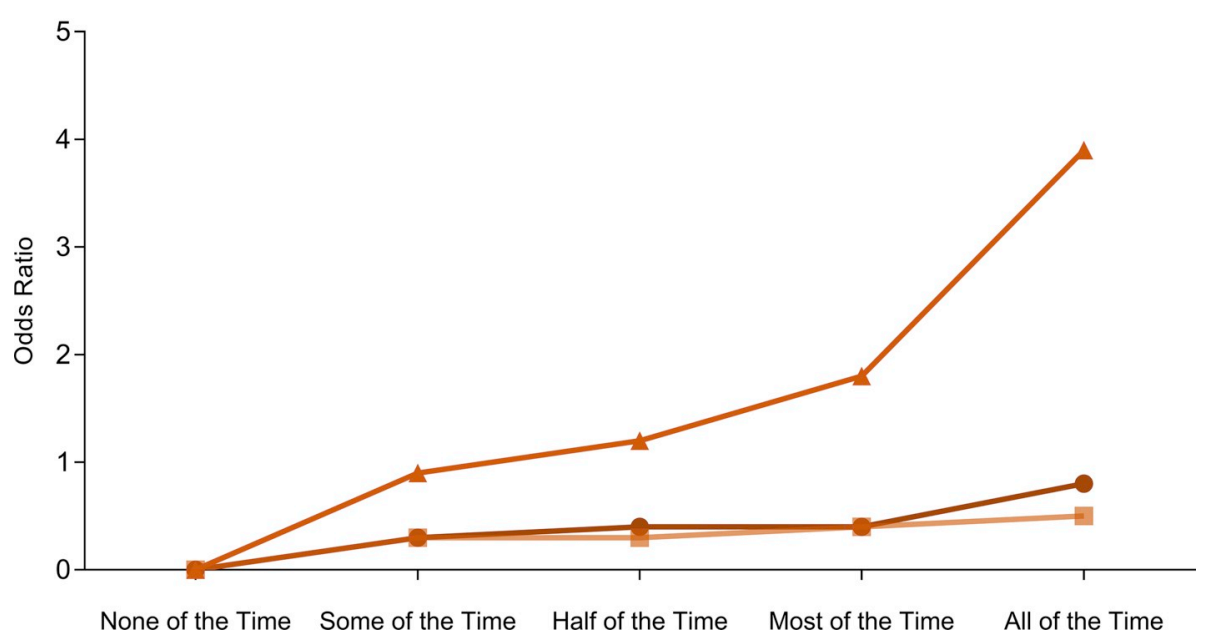

Fig. 4. Incidence of severe heat stress cases and exposure. 


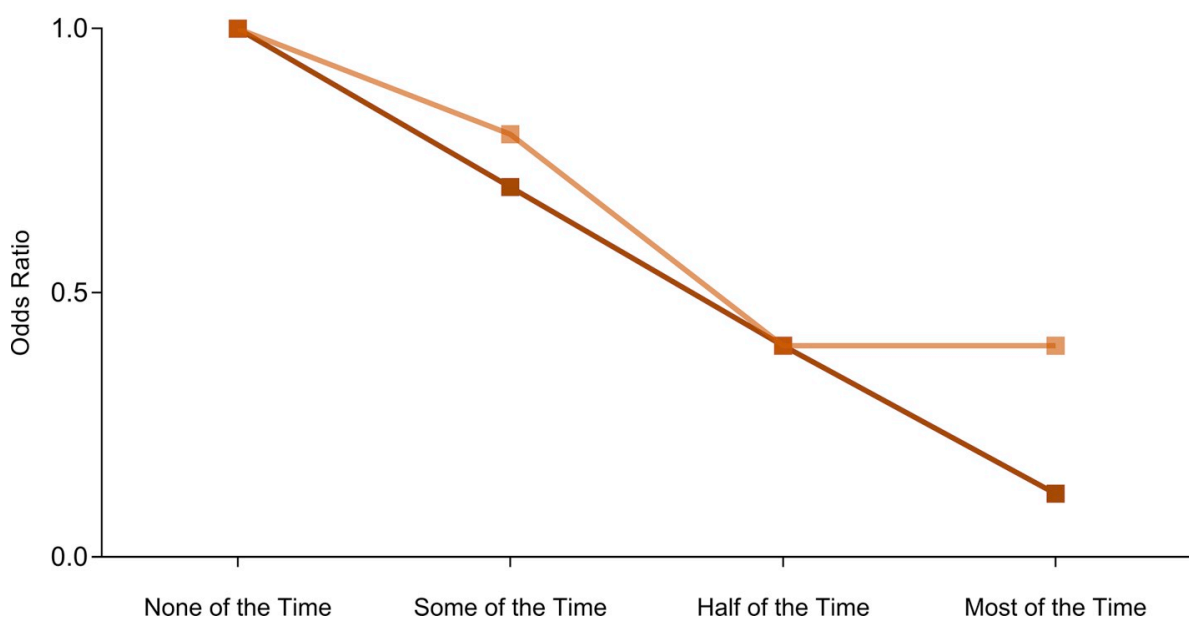

Fig. 5. Chronic and severe heat stress cases with air-conditioning exposure (Odds ratio).

Whereas government, emergency, public administration and safety workers demonstrated a strong negative association with increased exposure to outdoor conditions. This demarcation between industries may be due to transient workplace exposure and access to air-conditioning, which can enhance evaporative cooling and reduce heat stress symptoms (Hunt, 2011; Shapiro et al., 1982) and may justify the implementation of mandatory cooling breaks for workers exposed to multiple heat sources within other industries.

\subsection{Negative impacts within workplace settings}

Exposure to heat sources within the workplace can have detrimental effects on workplace productivity. Within this study, all negative impacts demonstrated a strong association with both chronic and severe heat stress symptoms. Commonly reported by workers (35\% daily or weekly), fatigue can manifest in reduced physical work capacity and cognitive performance (Bandelow et al., 2010). Indeed, cognitive impairment is implied, reported by workers via their inability to focus on tasks, decreased attention to small details, and decreased ability to understand tasks. Physical fatigue is inferred by inferior quality of work and speed of task completion, however, slower speed of task completion could also be evidence of self-pacing to minimise elevations in body temperature (Brearley et al., 2017; Donoghue et al., 2000; Hunt, 2011). Irrespective of origin, an implication of heat exposure, fatigue and self-pacing within the workplace is a reduced work capacity and performance (Snook and Ciriello, 1974).

Undoubtedly, feelings of discontentment can arise from unproductive settings and reduce satisfaction within the working environment. Workers perceived heat to impact job satisfaction on a daily or weekly basis, congruent with other studies conducted in hot occupational settings (Dawal and Taha, 2006; Dehghan et al., 2016; Dianat et al., 2016). Further, a total of 30 workers reported between 63 and 89 days of sick leave due to heat-related illness, while only 15 workers sought medical attention. It is unknown whether the remaining 15 workers resolved their symptoms or persisted through the shift without treatment, the latter potentially reducing productivity and increasing discontentment. Overall, the self-reported physical and mental impacts may reduce staff productivity, job satisfaction and contribute to increased staff turnover in the Monsoonal North (Zander et al., 2016; Zoellner et al., 2017).

\subsection{Negative impacts within home settings}

The home setting, particularly in arduous environments, provides a

Table 4

Regression analysis of heat cases and negative impacts.

\begin{tabular}{|c|c|c|c|c|c|}
\hline \multirow{2}{*}{ Variable } & & \multicolumn{2}{|l|}{ Chronic cases } & \multicolumn{2}{|l|}{ Severe cases } \\
\hline & & OR $(95 \% \mathrm{CI})$ & $p$ value & OR $(95 \% \mathrm{CI})$ & $p$ value \\
\hline \multirow[t]{10}{*}{ Work Environment } & Speed of task completion & $5.8(2.9-11.8)$ & $<0.001$ & $2.5(1.5-4.2)$ & $<0.001$ \\
\hline & Motivation to complete task & $4.5(2.4-8.6)$ & $<0.001$ & $3.2(1.8-5.3)$ & $<0.001$ \\
\hline & Job satisfaction & $3.2(1.7-5.9)$ & $<0.001$ & $2.6(1.6-4.0)$ & $<0.001$ \\
\hline & Physical work & $4.1(2.1-7.8)$ & $<0.001$ & $2.2(1.4-3.5)$ & 0.001 \\
\hline & Ability to focus on task & $2.8(1.6-5.1)$ & $<0.001$ & $3.2(2.0-5.3)$ & $<0.001$ \\
\hline & Attention to small detail & $2.8(1.5-5.2)$ & 0.001 & $3.7(2.2-6.2)$ & $<0.001$ \\
\hline & Quality of work & $2.8(1.5-5.2)$ & 0.001 & $3.0(1.8-5.0)$ & $<0.001$ \\
\hline & Ability to understand task & $2.8(1.4-5.6)$ & 0.004 & $3.5(2.1-5.9)$ & $<0.001$ \\
\hline & Sick leave & $0.5(0.2-1.2)$ & 0.117 & $4.7(1.9-11.7)$ & 0.001 \\
\hline & Medical treatment & $0.5(0.2-1.5)$ & 0.209 & $3.5(1.1-11.5)$ & 0.037 \\
\hline \multirow[t]{6}{*}{ Home Environment } & Sport & $1.7(1.0-2.7)$ & 0.026 & $1.8(1.3-2.7)$ & 0.002 \\
\hline & Sleep & $3.1(1.7-5.5)$ & $<0.001$ & $2.6(1.7-4.1)$ & $<0.001$ \\
\hline & Appetite & $4.7(2.4-9.1)$ & $<0.001$ & $3.3(2.1-5.3)$ & $<0.001$ \\
\hline & Recreational activity & $2.5(1.4-4.2)$ & 0.001 & $1.8(1.2-2.8)$ & 0.004 \\
\hline & Wellbeing & $2.6(1.4-4.6)$ & 0.001 & $2.9(1.8-4.5)$ & $<0.001$ \\
\hline & Friends and family & $2.5(1.4-4.7)$ & 0.003 & $2.8(1.8-4.5)$ & $<0.001$ \\
\hline
\end{tabular}

Odds ratio (95\% Confidence interval). 
place of solace and respite for workers. The burden of physical labour within a hot and humid environment potentially extends into periods of rest, which is demonstrated by workers responses in this study. Diminished sleep was reported by $29 \%$ of workers resulting in tiredness, decrements in cognition, and compounding the effects of heat and sleep loss in proceeding days (Halson, 2014; Killgore, 2010). The implication of sleep deprivation or poor quality of sleep on work is dangerous in physical work places, particularly where the use of heavy machinery and vehicles are part of the daily work tasks. Most work places have mandatory stand-down periods between shifts to limit the dangers of sleep loss and fatigue in an effort to keep workers safe, however, if sleep is disrupted or lost the assumption that a worker is well-rested at the beginning of a shift is a potential hazard. Additionally, reduced appetite reported by $27 \%$ of workers, can increase dehydration through inadequate nutritional intake and solute depletion (Maughan et al., 1996), which in turn can further exeracerbate fatigue and increase the risk of workplace injury.

It is also prudent to consider the impacts of heat extending to personal relationships, which serve to provide workers life satisfaction and happiness (Siedlecki et al., 2014). A portion of workers (18\%) reported heat negatively affecting relationships with friends and family, increasing exponentially with symptom severity. Moreover, participation in recreational sporting and exercise activities, known to increase mental wellbeing and health (Pate et al., 1995; Warburton et al., 2006), was also negatively impacted by heat exposure. These findings suggest that some workers in the Monsoonal North are unlikely to fully recover from workplace heat exposure on a daily basis, as the impact of the work shift extends into their personal lives, affecting them physically and mentally. The repercussions of decreased satisfaction, happiness, health and activity status may impact mental health outcomes, demonstrated by the prevalent homicide, serious assault and suicide rates at times of peak temperatures and humidity (build-up and wet season) within the Monsoonal north (McDermott et al., 2017). Further evidence of the ill effects of heat on mental health are demonstrated with increased hospital admission for behavioural and mental health issues during times of peak temperatures (Hansen et al., 2008) with further associations with sleep loss and reduced exercise (Tawatsupa et al., 2012).

\subsection{Limitations}

Whilst this cross-sectional study highlights health and safety concerns for both worker and employer, inherent limitations should be considered when reviewing the results. Due to the voluntary nature of this study, nonresponse bias may have led to an over-representation of symptomatic workers. Moreover, descriptive results and regression analysis cannot be declared causal relationships, as risk and outcomes were measured simultaneously, with possible confounding effects. Whilst small sample sizes from varied job roles may have affected results, grouping within statistical analysis endeavoured to offset these possible effects.

In contrast with longer-term studies, this research aimed to elicit smaller timeframes between reported symptoms and exposures, increasing the likelihood that same day or weekly symptoms were occurring and more indicative of heat illness. Moreover, targeting the 'build up' season within the Monsoonal North was to capture the harshest environmental conditions of the year for workers, and therefore, most likely to elicit responses of heat illness. However, this analysis was unable to discern the time of symptoms relative to exposure, or whether they occurred prior to or after exposure.

\section{Conclusions}

The purpose of this study was to verify the prevalence of heat stress symptoms within labour-intensive industries within the Monsoonal North, demonstrating most workers perceived to be suffering from both chronic and severe heat stress symptoms. This study identified self-reported productivity, wellbeing and health issues were associated with occupational heat exposure, specifically increased exposure to heat sources resulting in more perceived symptoms by workers. It should be noted that strong associations were found between tradespersons and related workers, presumably due to their consistent outdoor exposure and proximity to radiant heat sources such as machinery, vehicles, and direct sunlight. Such data highlights either inadequacy within current policy or adherence to said policy within this industry, requiring more attention to reduce heat stress symptoms in future. For example, workers exposed to transient workplaces and air-conditioning, such as government employees managed to mitigate these potential adverse effects even within similar occupations. Whilst time in air-conditioning may reduce the effects of heat exposure, other efforts such as increased air movement within workplaces which cannot be air-conditioned may be feasible options for the mitigation of heat stress symptoms via evaporative cooling. The implications of increased heat exposure on worker productivity, wellbeing and health are considered requisite for continuous worker health and safety and to maintain permanency in a transient workforce. Finally, with the projected temperature increases across Australia, policy should be aimed at long-term robust heat stress policies specific to occupations based on their level of exposure to heat sources.

\section{Declarations of interest}

None.

\section{Funding}

This research did not receive any specific grant from funding agencies in the public, commercial, or not-for-profit sectors.

\section{Research data}

Whilst no personal identifiers were collected, due to the sensitive nature of some questions and size of workforce, respondents may be identifiable. Therefore, respondents were assured the responses would remain confidential. Ethics and participant consent were for the provision of written outputs only.

\section{Acknowledgements}

The authors acknowledge the assistance of the Heat Stress Research Partnership (Northern Institute, Charles Darwin University) including Ian Warrener, Mark Hankinson, and Amelia Seipel for their assistance with survey distribution.

\section{Appendix A. Supplementary data}

Supplementary data to this article can be found online at https:// doi.org/10.1016/j.apergo.2019.102918.

\section{References}

Anderson, C., 2016. Heat and violence. Curr. Dir. Psychol. Sci. 10 (1), 33-38. https://doi. org/10.1111/1467-8721.00109.

Australian Bureau of Meteorology, 2017. Climate Data Online. www.bom.gov.au/ climate/data/index.shtml?bookmark $=200$.

Bandelow, S., Maughan, R., Shirreffs, S., Ozgunen, K., Kurdak, S., Ersoz, G., Dvorak, J., 2010. The effects of exercise, heat, cooling and rehydration strategies on cognitive function in football players. Scand. J. Med. Sci. Sport. 20 (Suppl. 3), 148-160. https://doi.org/10.1111/j.1600-0838.2010.01220.x.

Brake, D., Bates, G., 2001. Fatigue in industrial workers under thermal stress on extended shift lengths. Occup. Med. 51 (7), 456-463. https://doi.org/10.1093/occmed/51.7. 456.

Brearley, M., 2016. Pre-deployment heat acclimatization guidelines for disaster responders. Prehospital Disaster Med. 31 (1), 85-89. https://doi.org/10.1017/S1049023X15005476.

Brearley, M., Harrington, P., Field, E., Oppermann, E., \& Lee, D. (Unpublished Results). Impact of Hot and Humid Work Conditions on Perceived Heat Stress Symptoms and Management Strategies - a Cross-Sectional Survey.

Brearley, M., Harrington, P., Lee, D., Taylor, R., 2015. Working in hot conditions-a study of electrical utility workers in the Northern Territory of Australia. J. Occup. Environ. 
Hyg. 12 (3), 156-162. https://doi.org/10.1080/15459624.2014.957831.

Brearley, M., Heaney, M., Norton, I., 2013. Physiological responses of medical team members to a simulated emergency in tropical field conditions. Prehospital Disaster Med. 28 (2), 139-144. https://doi.org/10.1017/S1049023X12001847.

Brearley, M., Norton, I., Trewin, A., 2017. The case for heat acclimatization of disaster responders-an Australian perspective. Front. Pub. Health 5, 98. https://doi.org/10. 3389/fpubh.2017.00098.

Brearley, M., Norton, I., Trewin, T., Mitchell, C., 2011. Fire Fighter Cooling in Tropical Field Conditions. National Critical Care and Trauma Response Centre.

Commonwealth Scientific and Industrial Research Organisation and Bureau of Meteorology, 2015. Climate Change in Australia Information for Australia's Natural Resource Management Regions. CSIRO and Bureau of Meteorology, Australia. Retrieved from https://www.climatechangeinaustralia.gov.au/media/ccia/2.1.6/ cms_page_media/168/CCIA_2015_NRM_TechnicalReport_WEB.pdf.

Commonwealth Scientific and Industrial Research Organisation and Bureau of Meteorology, 2016. State of the Climate 2016. Bureau of Meteorology, Melbourne, Australia Commonwealth of Australia Retrieved from. http://www.bom.gov.au/ state-of-the-climate/State-of-the-Climate-2016.pdf.

Cotter, J., Roberts, W., Amos, D., Lau, W., Priggs, S., 2000. Soldier Performance and Heat Strain during Evaluation of a Combat Fitness Assessment in Northern Australia. (DSTO-TR-1023). Defence Science \& Technology Organisation, Melbourne.

Dawal, S., Taha, Z., 2006. The effect of job and environmental factors on job satisfaction in automotive industries. Int. J. Occup. Saf. Ergon. 12 (3), 267-280. https://doi.org/ 10.1080/10803548.2006.11076687.

Dehghan, H., Mobinyzadeh, V., Habibi, P., 2016. The effects of heat stress on job satisfaction, job performance and occupational stress in casting workers. Jundishapur J. Health Sci. 8 (3). https://doi.org/10.17795/jjhs-36192.

Dianat, I., Vahedi, A., Dehnavi, S., 2016. Association between objective and subjective assessments of environmental ergonomic factors in manufacturing plants. Int. J. Ind. Ergon. 54, 26-31. https://doi.org/10.1016/j.ergon.2015.12.004.

Donoghue, A., Sinclair, M., 2000. Miliaria rubra of the lower limbs in underground mi ners. Occup. Med. 50 (6), 430-433. https://doi.org/10.1093/occmed/50.6.430.

Donoghue, A., Sinclair, M., Bates, G., 2000. Heat exhaustion in a deep underground metalliferous mine. Occup. Environ. Med. 57 (3), 165-174. https://doi.org/10.1136/ oem.57.3.165.

Fahed, A.k., Ozkaymak, M., Ahmed, S., 2018. Impacts of heat exposure on workers' health and performance at steel plant in Turkey. Engineering Science and Technology. Int. J. https://doi.org/10.1016/j.jestch.2018.05.005.

Giahi, O., Darvishi, E., Aliabadi, M., Khoubi, J., 2015. The efficacy of radiant heat controls on workers' heat stress around the blast furnace of a steel industry. Work 53 (2), 293-298. https://doi.org/10.3233/WOR-152104.

Glazer, J., 2005. Management of heatstroke and heat exhaustion. Am. Fam. Physician 71 (11), 2133-2140.

Hall, D.M., Baumgardner, K.R., Oberley, T.D., Gisolfi, C.V., 1999. Splanchnic tissues undergo hypoxic stress during whole body hyperthermia. Am. J. Physiol. Gastrointest. Liver Physiol. 276 (5), G1195-G1203. https://doi.org/10.1152/ajpgi. 1999.276.5.G1195.

Halson, S., 2014. Sleep in elite athletes and nutritional interventions to enhance sleep. Sport. Med. 44 (Suppl. 1), S13-S23. https://doi.org/10.1007/s40279-014-0147-0.

Hanna, E.G., Kjellstrom, T., Bennett, C., Dear, K., 2011. Climate change and rising heat: population health implications for working people in Australia. Asia Pac. J. Public Health 23 (2 Suppl. 1), 14S-26S. https://doi.org/10.1177/1010539510391457.

Hansen, A., Bi, P., Nitschke, M., Ryan, P., Pisaniello, D., Tucker, G., 2008. The effect of heat waves on mental health in a temperate Australian city. Environ. Health Perspect. 116 (10), 1369-1375. https://doi.org/10.1289/ehp.11339.

Hunt, A., 2011. Heat Strain, Hydration Status, and Symptoms of Heat Illness in Surface Mine Workers. Ph.D.. Queensland University of Technology, Brisbane, Queensland, Australia.

Hunt, A., Parker, A., Stewart, I., 2013. Symptoms of heat illness in surface mine workers. Int. Arch. Occup. Environ. Health 86 (5), 519-527. https://doi.org/10.1007/s00420012-0786-0.

Hunt, A.P., Parker, A.W., Stewart, I.B., 2014. Heat strain and hydration status of surface mine blast crew workers. J. Occup. Environ. Med. 56 (4), 409-414. https://doi.org/ 10.1097/JOM.0000000000000114.

Jay, O., Brotherhood, J., 2016. Occupational heat stress in Australian workplaces. Temperature 3 (3), 394-411. https://doi.org/10.1080/23328940.2016.1216256.

Jia, A., Loosemore, M., Gilbert, D., Rowlinson, S., 2016. Shielding workers from heat stress: reconciling the paradoxes of protecting and production logics. In: Paper Presented at the 32nd Annual Conference of the Association of Researchers in Construction Management (ARCOM), Manchester, UK.

Killgore, W., 2010. Effects of sleep deprivation on cognition. Prog. Brain Res. 185, 105-129. https://doi.org/10.1016/B978-0-444-53702-7.00007-5.

Krishnamurthy, M., Ramalingam, P., Perumal, K., Kamalakannan, L., Chinnadurai, J., Shanmugam, R., Venugopal, V., 2017. Occupational heat stress impacts on health and productivity in a steel industry in southern India. Saf. Health Work 8 (1), 99-104. https://doi.org/10.1016/j.shaw.2016.08.005.
Lambert, G.P., Gisolfi, C.V., Berg, D.J., Moseley, P.L., Oberley, L.W., Kregel, K.C., 2002. Selected contribution: hyperthermia-induced intestinal permeability and the role of oxidative and nitrosative stress. 1985. J. Appl. Physiol. 92 (4), 1750-1761. https:// doi.org/10.1152/japplphysiol.00787.2001. discussion 1749 .

Maughan, R., Leiper, J., Shirrefs, S., 1996. Restoration of fluid balance after exerciseinduced dehydration: effects of food and fluid in-take. Eur. J. Appl. Physiol. 73 (3-4), 317-325. https://doi.org/10.1152/jappl.1997.83.4.1152.

McDermott, K., Brearley, M., Hudson, S., Ward, L., Read, D., 2017. Characteristics of trauma mortality in the northern territory, Australia. Inj. Epidemiol. 4 (1), 15. https://doi.org/10.1186/s40621-017-0111-1.

Notley, S.R., Meade, R.D., D'Souza, A.W., Friesen, B.J., Kenny, G.P., 2018a. Heat loss is impaired in older men on the day after prolonged work in the heat. Med. Sci. Sport. Exerc. 50 (9), 1859-1867. https://doi.org/10.1249/mss.0000000000001643.

Notley, S.R., Meade, R.D., Friesen, B.J., D'Souza, A.W., Kenny, G.P., 2018b. Does a prolonged work day in the heat impair heat loss on the next day in young men? Med. Sci. Sport. Exerc. 50 (2), 318-326. https://doi.org/10.1249/MSS.0000000000001444.

Nybo, L., 2008. Hyperthermia and fatigue. J. Appl. Physiol. 104 (3), 871-878. https:// doi.org/10.1152/japplphysiol.00910.2007.

Oppermann, E., Brearley, M., Law, L., Smith, J., Clough, A., Zander, K., 2017. Heat, health, and humidity in Australia's monsoon tropics: a critical review of the problematization of 'heat' in a changing climate. Wiley Interdiscip. Rev.: Clim. Change 8 (4), e468. https://doi.org/10.1002/wcc.468.

Pate, R., Pratt, M., Blair, S., Haskell, W., Macera, C., Bouchard, C., . W Wilmore, J., 1995 Physical activity and public health: a recommendation from the centers for disease control and prevention and the american college of sports medicine. J. Am. Med. Assoc. 273 (5), 402-407. https://doi.org/10.1001/jama.1995.03520290054029.

Patterson, M., Taylor, N., Amos, D., 1997. Tests of Cognitive, Perceptual and Sustained Attention Functions in Hot Environments. (DSTO-TR-0650). Defence Science and Technology Organisation, Melbourne, Australia.

Peiffer, J., Abbiss, C., 2013. Thermal stress in North Western Australian iron ore mining staff. Ann. Occup. Hyg. 57 (4), 519-527. https://doi.org/10.1093/annhyg/mes084.

Santamouris, M., Synnefa, A., Ulpiani, G., Haddad, S., Paolini, R., Garshasbi, S., 2017. Darwin City Deal - Heat Study Executive Report: Heat Mitigation Program Darwin, Northern Territory. Report Prepared for Northern Territory Government at the Faculty of Built Environment. University of New South Wales, Sydney, Australia Retrieved from. https://darwincitydeal.nt.gov.au/_data/assets/pdf_file/0008/ 442646/heat study executive summary.pdf.

Shapiro, Y., Pandolf, K.B., Goldman, R.F., 1982. Predicting sweat loss response to exercise, environment and clothing. Eur. J. Appl. Physiol. Occup. Physiol. 48 (1), 83-96. https://doi.org/10.1007/bf00421168.

Shapiro, Y., Seidman, D., 1990. Field and clinical observations of exertional heat stroke patients. Med. Sci. Sport. Exerc. 22 (1), 6-14.

Siedlecki, K., Salthouse, T., Oishi, S., Jeswani, S., 2014. The relationship between socia support and subjective well-being across age. Soc. Indic. Res. 117 (2), 561-576. https://doi.org/10.1007/s11205-013-0361-4.

Snook, S., Ciriello, V., 1974. The effects of heat stress on manual handling tasks. Am. Ind. Hyg. Assoc. J. 35 (11), 681-685. https://doi.org/10.1080/0002889748507088.

Steffen, W., Hughes, L., Alexander, D., Rice, M., 2017. Cranking up the Intensity: Climate Change and Extreme Weather Events. https://www.climatecouncil.org.au/uploads/ 1b331044fb03fd0997c4a4946705606b.pdf.

Stern, H., De Hoedt, G., Ernst, J., 2000. Objective classification of Australian climates. Aust. Meteorol. Mag. 49 (2), 87-96.

Tawatsupa, B., Yiengprugsawan, V., Kjellstrom, T., Seubsman, S.A., Sleigh, A., 2012. Heat stress, health and well-being: findings from a large national cohort of Thai adults. BMJ Open 2 (6). https://doi.org/10.1136/bmjopen-2012-001396.

Taylor, L., Watkins, S.L., Marshall, H., Dascombe, B.J., Foster, J., 2015. The impact of different environmental conditions on cognitive function: a focused review. Front. Physiol. 6, 372. https://doi.org/10.3389/fphys.2015.00372.

Warburton, D., Nicol, C., Bredin, S., 2006. Health benefits of physical activity: the evidence. Can. Med. Assoc. J. 174 (6), 801-809. https://doi.org/10.1503/cmaj.051351.

Xiang, J., Bi, P., Pisaniello, D., Hansen, A., 2014. The impact of heatwaves on workers' health and safety in Adelaide, South Australia. Environ. Res. 133, 90-95. https://doi. org/10.1016/j.envres.2014.04.042.

Xiang, J., Hansen, A., Pisaniello, D., Bi, P., 2016. Workers' perceptions of climate change related extreme heat exposure in South Australia: a cross-sectional survey. BMC Public Health 16, 549. https://doi.org/10.1186/s12889-016-3241-4.

Zander, K., Botzen, W., Oppermann, E., Kjellstrom, T., Garnett, S., 2015. Heat stress causes substantial labour productivity loss in Australia. Nat. Clim. Chang. 5 (7), 647-651. https://doi.org/10.1038/nclimate2623.

Zander, K., Surjan, A., Garnett, S., 2016. Exploring the effect of heat on stated intentions to move. Clim. Change 138 (1-2), 297-308. https://doi.org/10.1007/s10584-0161727-9.

Zoellner, D., Brearley, M., Oppermann, E., 2017. Regional disparities in apprentice attrition rates: heat and quarter four's significance in northern Australia. Int. J. Train. Res. 15 (2), 179-195. https://doi.org/10.1080/14480220.2017.1312694. 